\title{
Climate Variability, Risk and Paddy Production
}

\author{
W. K. A. M. A. Hasanthika ${ }^{1}$, J. C. Edirisinghe ${ }^{1,{ }^{*}}$ and R. D. D. P. Rajapakshe ${ }^{2}$ \\ ${ }^{1}$ Dept. of Agribusiness Management \\ Faculty of Agriculture and Plantation Management, \\ Wayamba University of Sri Lanka, Makandura, Gonawila (NWP) \\ ${ }^{2}$ Socio Economics \& Planning Centre \\ Department of Agriculture, Peradeniya \\ \# Corresponding Author:
}

Tele: (94) 71292 0578; Fax: (94) 31229 9246; E-mail: jagathed@yahoo.com

\begin{abstract}
The study hypothesized that increased variability in paddy yields is related with increased risk and investigate the impact of climatic and production factors on risk. A production function was estimated with related risk properties to see how variation in climatic variables and production factors affects the probability distribution of paddy yields. Data consisted of a panel of 6 major paddy growing districts for the period, 1980 to 2010 for the two major paddy growing seasons, Yala and Maha. A three step Feasible Generalized Least Squares method is used to estimate the production function with risk properties. Results reveal that climatic factors as rainfall, maximum temperature, and production factors such as labor, machinery cost and cultivation extents are positively related with the probability distribution of yield. Hence their variability tends to increase risk. This highlights the importance of crop insurance schemes and policies that reduce food insecurity in the light of expected climate change in the years to come.
\end{abstract}

KEYWORDS: Climate, Feasible Generalized Least Squares, Just and Pope Production Function, Risk

\section{Introduction}

In Agricultural production, there is a time lag between input decision making and production realization. Farm production decision marking depends on known input levels but uncertain levels of output, because of the inherent volatility of agricultural production (Mekki and Jemaa, 2007). Volatility in agriculture sector is explained by production volatility which is mostly driven by climate change as well as price. Higher production volatility affects the tight supply/demand balance. Decision-making under higher volatile and uncertain conditions always lead to risk (Schaffnit-Chatterjee, 2010). 
Risk can be defined as the potential deviation between expected and real outcomes. If there is high risk, it is difficult to make economic decisions. This volatile nature of agricultural production is due to uncontrollable elements, such as climatic factors. Climatic factors serve as direct inputs to agriculture. Any change in a climatic factor is bound to have a significant impact on crop yield and production. This area has caught attention of researchers in recent times as evident by the growing number of studies on the impact of climate change on agriculture (Barnwal and Kotani, 2010).

A wide variety of findings have pointed out regarding the effect of climate change on crop yields. Many studies find that climate change alters mean crop yields (Reilly et al., 2002; Schlenker and Roberts, 2009; Huang and Khanna, 2010). However, Greenstone and Deschenes (2007), find a statistically insignificant relationship between climate change and crop yields. Some other studies have addressed the contribution of climate change to yield variability (Chen, McCarl, and Schimmelpfennig, 2004; Isik and Devadoss, 2006; McCarl, et al., 2008). Moreover, the impact of the changes in crop yield induced by the change in climate has implications on the market outcomes and the welfare of economic units (Greenstone and Deschenes, 2007).

Agricultural sector is one of the key sectors in the Sri Lankan economy. The Goss Domestic Production (GDP) of the agricultural sector was $11.9 \%$ in 2010. It employed 33.7\% of the national labor force in 2010 (Central Bank, 2010). Paddy is one of the most important crops in Sri Lanka. It contributes to agricultural GDP by 11.9 per cent and by 1.8 per cent to the total GDP 2010 (Central Bank, 2010). Total land devoted for paddy is about 708,000 hectares at present.

Paddy occupies about 45 per cent of the total permanent agriculture land holdings (Census and Statistics, 2010) and is the main staple food product in Sri Lanka and also the main source of calories in the Sri Lankan diet. One of the main causes of food insecurity is the country's insufficiency of net rice production to meet household demand (Anon, 2007). Therefore, paddy production has high implications on food security of the nation. Therefore, it is vital that how variations in climate affect paddy production and its variability. Hence, this study attempts to model the impact of climatic variation on mean and variance (risk) of paddy yields in Sri Lanka.

\section{Methodology}

The effects of climate change and related risk condition to the average and variability of crop yields can be determine by using a stochastic production function. The production function suggested by Just and Pope $(1978,1979)$ 
provides a way to study the impact of independent variables on the mean production as well as the variability of production.

Therefore, this study used the Just and pope production function for analysis. There are two methods to estimate this function, a three-step Feasible Generalized Least squares (FGLS) method and Maximum Likelihood Estimation (MLE). This study employs a three-step, FGLS estimation. The Just and Pope Production function is of the form;

$$
\mathrm{Y}=f(\mathrm{X}, \beta)+\mu=f(\mathrm{X}, \beta)+h(\mathrm{X}, \alpha)^{0: 5} \varepsilon
$$

Where, $\mathrm{Y}$ is the output or yield, $\mathrm{X}$ is a vector of independent variables, $f($.$) denotes$ the deterministic component (mean function) of yield and relates $\mathrm{X}$ to average yield with $\beta$ representing the set of estimated coefficients. $\mu$ is the heteroskedastic disturbance term with a zero mean, $h($.$) is the stochastic component (variance$ function) of yield and relates $X$ to the standard deviation of yield with $\alpha$ representing the corresponding set of estimated coefficients. $\varepsilon$ is a random error term with a mean of zero and variance of $\sigma^{2}$.

The three step FGLS takes following steps. First, the model was estimated by Ordinary Least Squares (OLS) regression and the $\mathrm{n}$ residuals $(\hat{\mu})$ are obtained.

$$
\mathrm{Y}=f(\mathrm{X}, \beta)+\mu
$$

Second, the logarithm of squared residuals was regressed on $\mathrm{X}$.

$$
\ln (\hat{\mu})=h(\mathrm{X}, \alpha)+\varepsilon
$$

Using this second stage estimation, variances are predicted. Using the square roots of these variances as weights, the original model was re-estimated using a Weighted Least Squares (WLS) technique as;

$$
y \cdot h^{-1 / 2}(\mathrm{X}, \hat{\wedge} \alpha)=f(\mathrm{X}, \beta) \cdot h^{-1 / 2}(\mathrm{X}, \hat{} \alpha)+\mu h^{-1 / 2}(\mathrm{X}, \hat{} \alpha)
$$

labor, machinery cost, fertilizer cost, extent of paddy cultivation, total rainfall in the season, maximum temperature and minimum temperature which is calculated as average temperature for the season and a time trend were incorporates as $\mathrm{X}$ matrix. Before estimating, the FGLS, all data were tested for unit roots and confirmed that they are stationary. The three step FGLS was estimated for both the Random Effect (RE) and the Fixed Effects (FE) model keeping in line with the panel data literature by using Housman tests. Stata version 9.2 was used to estimate the regression. 


\section{Results and Discussion}

\section{Descriptive Statistics}

Data source of this study was 'Cost of cultivation of Agricultural crops` published by the Department of Agriculture. Time series data were used from 6 major paddy growing districts (Anuradhapura, Polonnaruwa, Kurunegala, Hambanthota, Kandy and Kaluthara), in the two major growing seasons; Maha (September to February in the following year) and yala (March to August). Thus, the data set consisted of a panel from 1980 to 2010 .

The major paddy irrigation types are there major irrigation and rain fed. Three variables were included as climate variables such as total rainfall, maximum temperature and minimum temperature. Total rainfall calculated according to the yala and Maha season. Maximum temperature and minimum temperature calculated as average temperature value during the season. Total labor, machinery cost, fertilizer cost, extent of paddy cultivation, data were used as production data.

Total labor was calculated as man days. Extent of paddy cultivation is in Acers. The average total rainfall amount is $941.43 \mathrm{~mm}$ in these paddy growing areas. The average cultivated extent is 39557.64 Acers. The average minimum and maximum temperature values are $23.72{ }^{\circ} \mathrm{C}$ and $31.72{ }^{\circ} \mathrm{C}$. Total rainfall, maximum temperature and minimum temperature in Maha and Yala season over the 31 years of period are shown in following Figure 1.

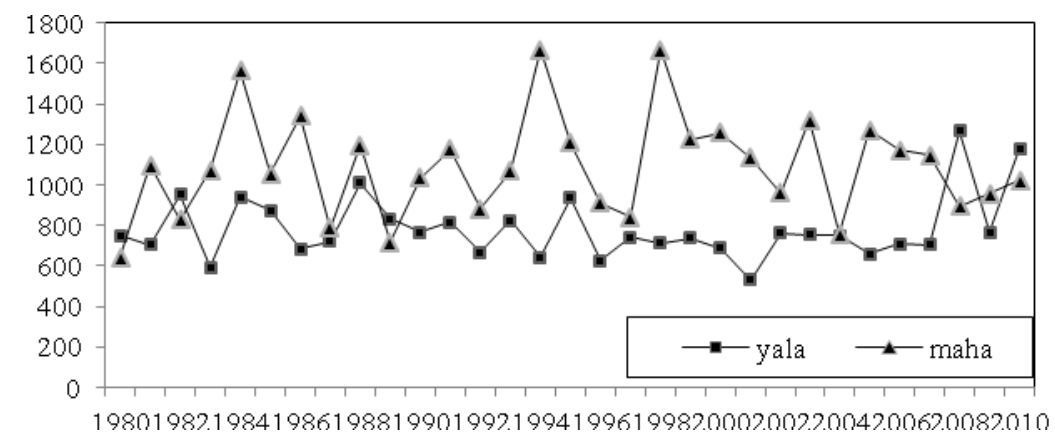

(a) 


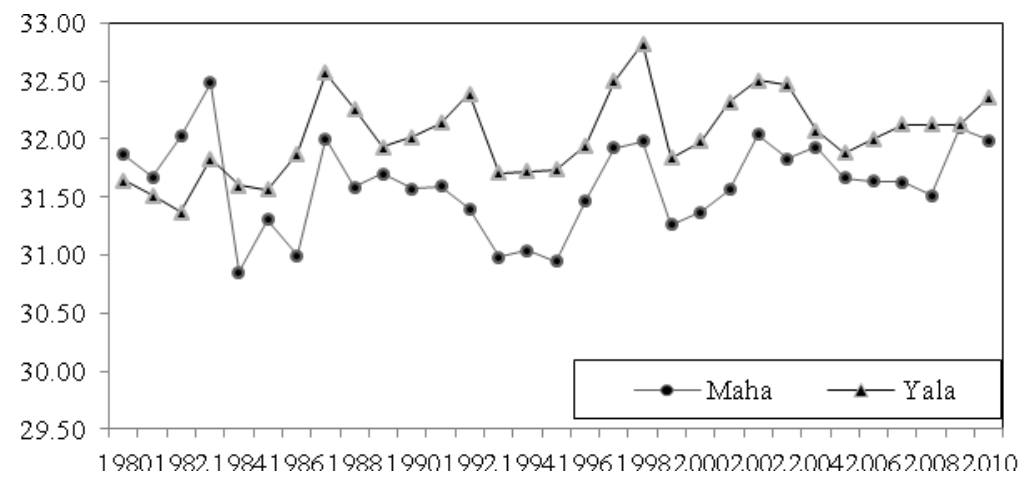

(b)

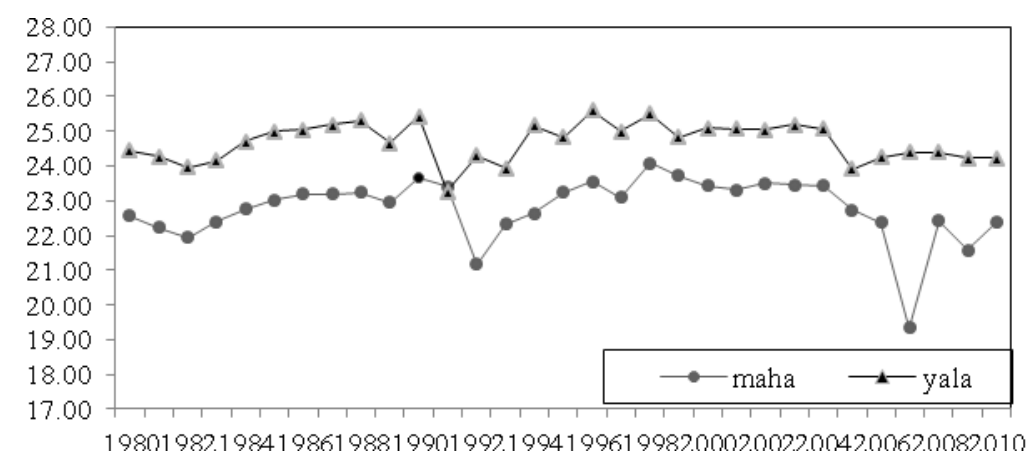

(c)

Figure 1: Variation in climate variables in Maha and Yala Season (1980 2010): (a) Total rainfall, (b) Average maximum temperature (c) Average minimum temperature

It revealed that the amount of annual rainfall in Maha season is greater than Yala season except 2008 and 2010. The average maximum temperature in both seasons is distributed in almost similar Pattern. The average maximum temperature in both season distributed in almost similar pattern.

\section{Results of FGLS Estimation}

Hausman tests confirmed that the Random Effects (RE) model performs better and therefore, the discussion follows is related to the RE model estimated. The results of the variance function (Equation 3) show that climatic factors, which are rainfall, minimum temperature and the production variables as labor, machinery cost and 
extent of paddy cultivation have a positive relationship with the yield variability (Table 1). The maximum temperature, time trend and fertilizer cost have negative relationship with yield distribution.

Table 1: Parameter estimates from the FGLS variance equation

\begin{tabular}{llllc}
\hline \multicolumn{1}{c}{ Variable } & Coef. & Std. Err. & $\mathbf{Z}$ & $\mathbf{p}>\mid \mathbf{t}$ \\
\hline Rainfall & $0.001 *$ & 0.0003 & 2.77 & .006 \\
Temp.min & 0.026 & 0.046 & 0.57 & .569 \\
Temp.max & -0.066 & 0.124 & -0.5 & .595 \\
Labour & $2.91 \times 10^{-7}$ & $2.62 \times 10^{-7}$ & 1.11 & .266 \\
Machinery & $1.17 \times 10^{-8}$ & $8.02 \times 10^{-9}$ & 1.46 & .144 \\
Fertilizer & $-3.0 \times 10^{-8} *$ & $1.48 \mathrm{ex} 10^{-8}$ & -2.0 & .043 \\
Extent & $8.00 \times 10^{-6}$ & 0.000012 & 0.67 & .505 \\
Time & $-0.005^{*}$ & 0.0017 & -3.23 & .001 \\
cons & $31.839^{*}$ & 3.950 & 8.06 & .000 \\
\hline
\end{tabular}

*Significant at 5\%. Probability 0.000 R2=55.37\%

The results of the mean function show that, climatic factors as rainfall, minimum temperature and fertilizer cost negative effect to the mean yield (Table 2). But the maximum temperature and other production factors as labor, machinery cost, time trend, extent of paddy cultivation have a positive relationship with the mean yield distribution.

Table 2: Parameter estimates from the FGLS - mean equation

\begin{tabular}{lrrrr}
\hline \multicolumn{1}{c}{ Variable } & Coef. & Std. Err. & $\mathbf{Z}$ & $\mathbf{p}>|\mathbf{t}|$ \\
\hline Rainfall & $-16185.0^{*}$ & 4290.66 & -3.77 & 0.000 \\
Temp.min & $-125046^{* *}$ & 656484.6 & -1.90 & 0.057 \\
Temp.max & 705147 & 489247.6 & 0.44 & 0.150 \\
Labour & $6.12^{*}$ & 2.70 & 2.26 & 0.024 \\
Machinery & $0.48^{*}$ & 0.120 & 3.98 & 0.000 \\
Fertilizer & -0.126 & 0.227 & -0.56 & 0.577 \\
Extent & 1808.60 & 173.00 & 10.45 & 0.505 \\
Time & 344.70 & 20333.4 & .02 & 0.986 \\
cons & 2489046 & 1586422 & 1.57 & 0.117 \\
\hline
\end{tabular}

*Significant at 5\%**Significant at $10 \%$

Probability $0.000 \quad R^{2}=99.74 \%$ 
Increases in amount of rainfall leads to high yield variability and a decline in the mean yield. However, Barnwal and Kotani, (2010) reports that increase in total precipitation reduce the yield variability for most of the agro-climatic zones in India. But, if rainfall variability is associated with an untimely at the reproductive or ripening stage of the rice crop, yield reduction is severe as found in Bangladesh (Jayanta, 2007). There is considerable variation on the changes in rainfall patterns, the degree of severity and the geographic effects are to be expected in Sri Lanka (Eriyagama et al 2010). Therefore, mitigating the impact of rainfall on yield variation is important.

The degree of enhancement of $\mathrm{CO}_{2}$ was related to the maximum temperature. The process of photosynthesis in paddy is constant at about $60 \%$, from 32 to 38 degrees of Celsius (Vu et al, 1997). Therefore maximum temperature related to reduce the risk of paddy production. Previous studies have used the average temperature to study the impact of temperature on paddy yields and finds that average temperature is associated with a decline in the yields (Barnwal and Kotani, 2010).

Instead, we have used average minimum and maximum temperatures in the relevant growing seasons. Although not significant, increases in the minimum temperature show a positive sign with the yield variability and a negative sign with the mean yields. This implies that increases in minimum temperature increases variability and thus increases yield risk. Contrastingly, the maximum temperature returned opposite signs to that of minimum temperatures. Further studies with longer term time series data needs to be carried out to see the true impacts of the minimum and maximum temperatures on paddy yields.

Production factors as labor, machinery cost and extent of paddy cultivation reduce the yield variability and therefore, the risk. Although, fertilizer was found to be reducing risk, a previous study found that fertilizer, crop area and labor are risk increasing factors (Rento et. al., 2005).

\section{Conclusion}

The findings of this research suggest for policies related to food security and crop insurance schemes. As the yields are expected to vary due to climatic and economic factors, the impact of variation in yields will reflect upon the food security of peasant farmers. Policies should be directed at promoting crop insurance schemes and those that can reduce food insecurity in the light of expected changes in rainfall and temperatures due to climate change.

This study can be further extended to yield forecasting for various climate scenarios, which will be useful for an assessment of future risk and trends in crop yields. One major limitation of the study is that it had to rely upon climate data of a 
few meteorological stations and generalize it to the districts studied. Future studies of this kind should circumvent these limitations by collecting more relevant data

\section{References}

Annual Report (2010) Central Bank of Sri Lanka, Colombo

Anon (2007). Integrated Food Security and Humanitarian Phase Classification. IPC Learning and Planning. Nairobi, Kenya. Available from: www.ipcinfo.org. AttachmentsIPCLLWorkshop. (Accessed date $10^{\text {th }}$ July 2011)

Barnwal, P. and Kotani, K. (2010). Impact of variation in climatic factors on crop yield: A case of rice crop in Andhra Pradesh, India, IUJ Research Institute International University of Japan.

Census and Statistics of Sri Lanka (2010). Department of Agriculture and Environment Statistics Division. Available from: http://www.statistics.gov.lk/ agriculture/index.htm. (Accessed 30 May 2011).

Chen, C. C., McCarl, B. A. and Schimmelpfennig, D.E. (2004). Yield Variability as Influenced by Climate. 'Climatic Change, 66, 239-61.

Eriyagama, N., Vladimir, S. and Lalith, C., (2007). Impact on climatic changes on water resources and agriculture in Sri Lanka. IWMI research report. Available from: http://ccsl.iccip.net/rr. (Accessed 30 May 2011).

Greenstone, M., Deschenes, O., (2007) The Economic Impacts of Climate Change. Agricultural Profits and Random Fluctuations in Weather, 4 (26)

Huang, H. and Khanna, M. (2010) An Econometric Analysis of U.S. Crop Yield and Cropland Acreage: In proceedings of selected Paper presented at the AAEA, 25-27. July, 2008. Denver, Colorado.

Isik, M. and Devadoss, S. (2006) An analysis of the impact of climate change on crop yields and yield variability. Applied Economics, 38, 835-844.

Jayanta, K. B. (2007) Climate Change Impacts on Rice Production in Bangladesh: Results from a Model, Available from: www.unnayan.org. (Accessed 20 June 2011).

McCarl, B. A., X. Villavicencio, and X. Wu. (2008). Climate Change and Future Analysis American Journal of Agricultural Economics, 20, 1241-47.

Mekki, M. and Jemaa, B. (2007). Yield uncertainty and risk aversion in duality models a Mean-Variance approach. Available from: http://www.tn.refer.org (Accessed 30 May 2011). 
Reilly, J. M., J. Graham, D. G. Abler, R. Darwin, S. Hollinger, C. and Izaurralde, S. (2002). Changing Climate and Changing Agriculture Report of the Agricultural Sector Assessment Team, Cambridge, UK: Cambridge University.

Schlenker, W. and M.J. Roberts. (2009). Nonlinear Temperature Effects Indicate Severe Damages to U.S. Crop Yields under Climate Change. the National Academy of Sciences, 106 (37) 154-159

Schaffnit-Chatterjee. (2010). Risk management in agriculture. Deutsche Bank Research Frankfurt am Main Germany, Available from: http://ageconsearch.umn.edu/bitstream (Accessed 20 June 2011).

Vu, J. C. V., Allen, L. H., Boote, K. J. and Bowes, G. (1997). Effects of elevated $\mathrm{CO}_{2}$ and temperature on photosynthesis and Rubisco in rice and soybean, Plant Cell and Environment, 20 (1), 68-76 